\title{
18
}

\section{Characterization of Urban Green Roofs' Stormwater Runoff}

\author{
Jieyun Chen, James Li, and Barry Adams
}

Green roofs are considered as one of the green technologies towards the development of sustainable urban environment and the building of ecofriendly cities. The benefits of implementing green roofs are numerous such as increase of biodiversity and reduction of urban heat island effect, stormwater management, energy saving, air quality improvement, etc. From the perspective of stormwater control, as more and more rooftops in the urban area turns into green spaces, characteristics of stormwater runoff from the drainage area may undergo a significant change which inevitably exerts potential impacts on the existing and yet-to-be-built drainage systems. However, in addition to peak flow reduction, basic understanding of the characteristics of green roof stormwater runoff is either lacking or very limited, and referenced green roof studies are very few in the literature. In this study, based on a set of rooftop-monitored data including the antecedent soil moisture content, rainfall, runoff volume and peak flow rates, stormwater runoff from both the roof garden area and the control area (the original rooftop without greening) was analyzed for its characteristics. It is well known that the antecedent soil moisture content is an important parameter associated with runoff generation, whereas runoff coefficient is a direct measure of the rainfall-runoff transformation process. These fundamental relationships are characterized in an attempt to better understand runoff generation mechanisms from green roofs. As part of this study for stormwater runoff characterization, probability distributions were

Chen, J., J. Li and B.J. Adams. 2009. "Characterization of Urban Green Roofs' Stormwater Runoff." Journal of Water Management Modeling R235-18. doi: 10.14796/JWMM.R235-18.

(C) CHI 2009 www.chijournal.org ISSN: 2292-6062 (Formerly in Conceptual Modeling of Urban Water Systems. ISBN: 978-0-9808853-2-3) 
fitted to sample data of the rainfall, runoff volumes and peak flow rates monitored from the green roof and control area, respectively. The statistical behavior of stormwater runoff from the two areas is evaluated and the best fit probability distribution may be determined. It is of interest to determine if some commonly used probability distributions can be used to fit green roof stormwater data as well.

\subsection{Introduction}

Stormwater management has evolved from centralized downstream control to decentralized local control at the source. Green roofs are considered to be one of many low impact development techniques for stormwater management. Conceptually, green roofs are pervious areas and produce less runoff. However, the runoff characteristics from green roofs are not well understood as both the soil as well as the plant species will affect the runoff. There have been a number of field studies of stormwater from green roofs. Table 18.1 summaries the results of some of these studies. It is important to recognize that these green roofs and the associated meteorological conditions can be quite different. In general, the green roofs provided better control over peak flow $(60-80 \%)$ and runoff volume $(40-80 \%)$. The time delay of runoff varies between 45 to 200 minutes. While it is informative to know the average reduction of runoff volume and peak flow on an event basis, it is important to understand the statistical characteristics of storm runoff from a green roof. This study focuses on the characterization of the statistical properties of runoff from a green roof. The analysis was based on a two year monitoring program at a green roof in the City of Toronto (Toronto and Regions Conservation Authority, 2004).

\subsection{Description of Study Area}

Rooftop gardens have been widely recognized as effective facilities for providing numerous benefits to urban environment (Ryerson, 2005). As a result of growing interest in green roof planning and design, the City of Toronto has been developing a green roof policy since 2005, which includes a commitment to greening existing and new roofs on municipal buildings where feasible, and developing a pilot incentive program to assist with the capital costs of green roof construction (TRCA, 2007a). As part of the Sustainable Technologies Evaluation Program (STEP), a multi-agency program led by the Toronto and Region Conservation Authority (TRCA), 
the York University green roof garden was designed as an instrumental project for demonstration.

Table 18.1 Stormwater performance of green roofs.

\begin{tabular}{|c|c|c|c|c|}
\hline Authors & Location & $\begin{array}{c}\text { Average } \\
\text { volumetric } \\
\text { reduction (\%) }\end{array}$ & $\begin{array}{c}\text { Average peak } \\
\text { flow reduction } \\
(\%)\end{array}$ & $\begin{array}{l}\text { Average time } \\
\text { delay (min) }\end{array}$ \\
\hline Liesecke (1993) & Germany & 0.6 & & \\
\hline $\begin{array}{l}\text { Thompson } \\
\text { (1998) }\end{array}$ & & 0.8 & & \\
\hline Liesecke (1998) & Germany & 0.43 & & \\
\hline Liu (2003) & Ottawa & 0.54 & & 95 \\
\hline $\begin{array}{l}\text { Bass \& } \\
\text { Baskaran } \\
\text { (2003) }\end{array}$ & Ottawa & 0.39 & 0.8 & 45 \\
\hline $\begin{array}{l}\text { Jennings et al. } \\
\text { (2003) }\end{array}$ & Goldboro & 0.5 & & 198 \\
\hline $\begin{array}{l}\text { Toronto } \\
\text { Conservation } \\
\text { (2003) }\end{array}$ & Toronto & 0.65 & 0.68 & \\
\hline $\begin{array}{l}\text { Rowe et al. } \\
\text { (2003) }\end{array}$ & & 0.61 & & 198 \\
\hline Lipton (2003) & & 0.69 & & \\
\hline $\begin{array}{l}\text { Kohler \& } \\
\text { Schmidt (2004) }\end{array}$ & Germany* & 0.75 & & \\
\hline $\operatorname{Li}(2006)$ & Toronto & 0.41 & 0.42 & \\
\hline
\end{tabular}

Constructed in 2001 on the rooftop of the Computer Science and Engineering building at York University, the study area at the site actually consists of two surfaces: the conventional shingles referred to as the control roof, and the garden as shown in Figure 18.1. The garden with an area of $241 \mathrm{~m}^{2}$ consists of $140 \mathrm{~mm}$ of growing media and is vegetated with nonnative wildflowers. The size of the control roof is $131 \mathrm{~m}^{2}$. Both surfaces of the garden and control roof have a $10 \%$ slope without baffles. Stormwater from the two roof surfaces drains to Black Creek, a tributary of the Humber River watershed which empties into the Lake Ontario.

To address issues associated with stormwater management and evaluate the performance of the green roof, field data monitoring was conducted onsite for rainfall, stormwater runoff, soil moisture, relative humidity, air and growing medium temperature (TRCA, 2007b). Figure 18.2 shows locations 
of the monitoring instruments. Stormwater runoff from the garden and control roof was monitored continuously with two electromagnetic flow metres. It is important to recognize that these flow meters are good for measuring high flows and poor for low flows. Although rainfall at the site was measured using a tipping bucket rain gauge, long-term continuous rainfall data was obtained from Atmospheric Environment Service (AES) stations in the vicinity, and if necessary, this AES station may also provide back-up data on rain or snow conditions when site data is not available.

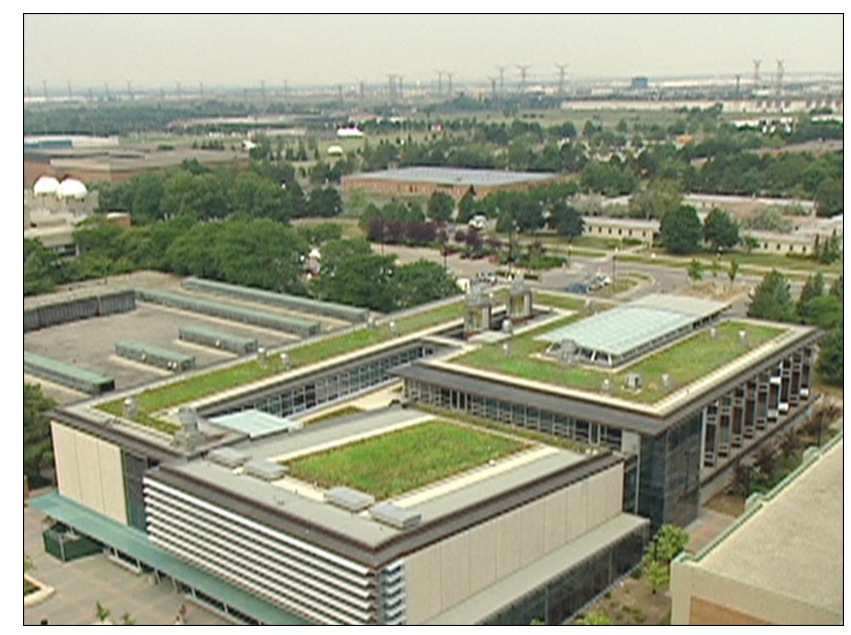

Figure 18.1 Green roof on the York University computer science building (source: TRCA 2004).

In this study, the real-time data monitored from the rooftop including rainfall, stormwater runoff, antecedent soil moisture, runoff coefficient are analyzed for its characteristics, and probability distributions are fitted to sample data. For this purpose, several commonly used probability distributions, e.g. normal, log normal and log Pearson distributions are selected, from which the best-fit probability distribution is determined. To better understand green roof hydrology, especially runoff generation mechanism, correlation analysis is performed for identification of prominent factors involved in rainfall-runoff transformation. It is expected that the characterization of stormwater runoff will enhance conceptual interpretation of major physical processes associated with rainfall-runoff transformation under green roof conditions, which contribute to fundamentals of green roof hydrology. 


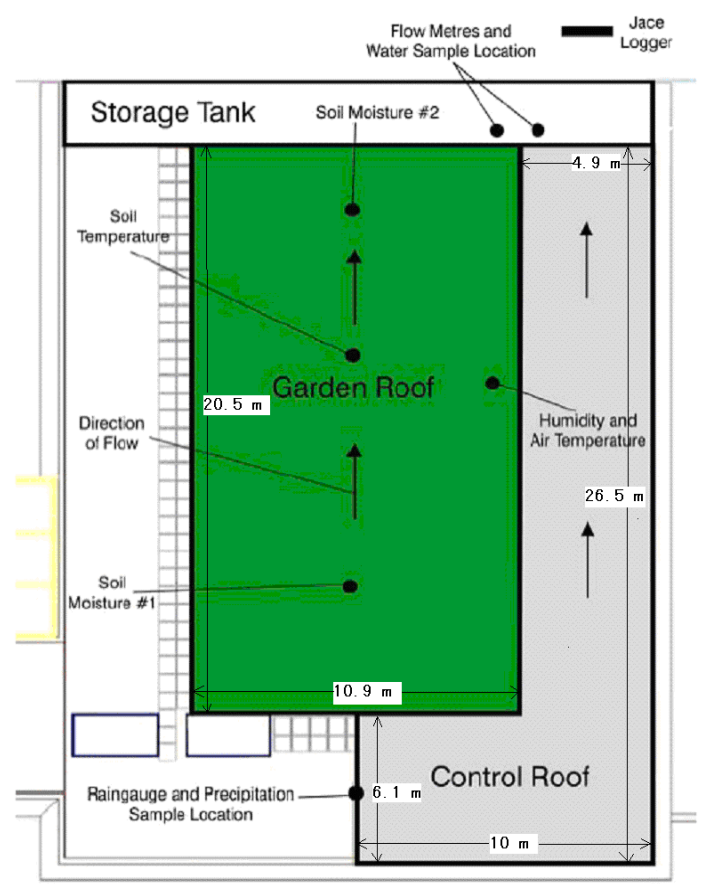

Figure 18.2 Schematic of garden roof and control roof (source: TRCA 2004).

\subsection{Rainfall Characteristics}

For real-time rainfall data monitoring and collecting, a tipping bucket rain gauge was installed on site and instantaneous rainfall data was observed for 2003, 2004 and 2005, based on which the annual rainfall depth is estimated. The annual rainfall depths for the three years are 964, 839 and $948 \mathrm{~mm}$, respectively, which are above the average annual rainfall depth of $793 \mathrm{~mm}$. During the three-year rainfall observation period, the maximum rainfall event volume of $48.6 \mathrm{~mm}$ was observed on July 20, 2004 at a time period from 13:19 to 15.30 with a mean rainfall intensity of $20.98 \mathrm{~mm} / \mathrm{hr}$.; whereas the maximum event rainfall intensity of $45.4 \mathrm{~mm} / \mathrm{hr}$ was observed on August 10,2003 at a time period from 16:03 to $16: 17$ with a rainfall depth of 10.6 $\mathrm{mm}$. Figure 18.3 shows scatter plots of the rainfall depth against intensity. The scattered points in the figure indicate that there is no obvious correlation between the rainfall depth and intensity. 


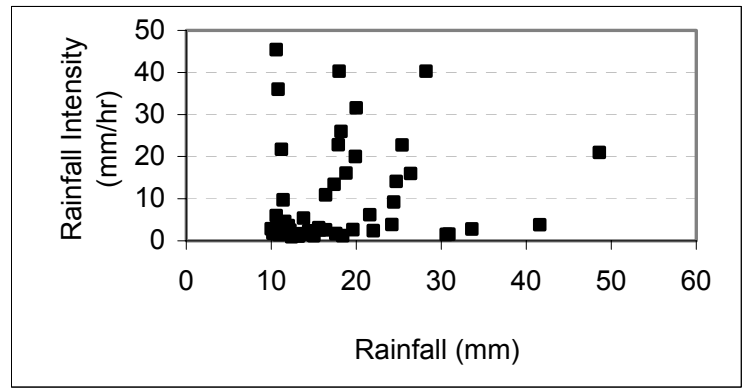

Figure 18.3 Rainfall depth vs. intensity.

To characterize rainfall statistics, several commonly used probability distributions, namely, normal, log normal and log Pearson distributions are fitted to the rainfall sample data as shown in Figures 18.4 and 18.5, respectively. Based on rainfall volume data (Figure 18.4), it is found that the $\log$ Pearson distribution fits the observed rainfall data better than either normal or log normal distribution, especially for those rainfall events with a relatively higher magnitude. By comparison, the normal and log normal distributions tend to underestimate rainfall event volumes. However, based on observed rainfall intensity data, Figure 18.5 indicates that the log Pearson distribution is more likely to overestimate rainfall intensity than the normal or lognormal distributions. But the normal distribution is more likely to underestimate rainfall intensity than the log normal and Log Pearson distributions. In other words, to avoid overestimating or underestimating rainfall intensity, the log normal distribution may be a better choice, which tends to provide an estimate in between.

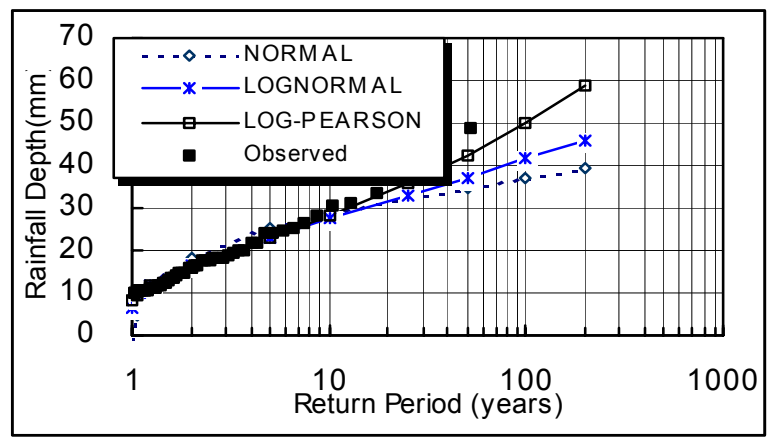

Figure 18.4 Rainfall depth. 


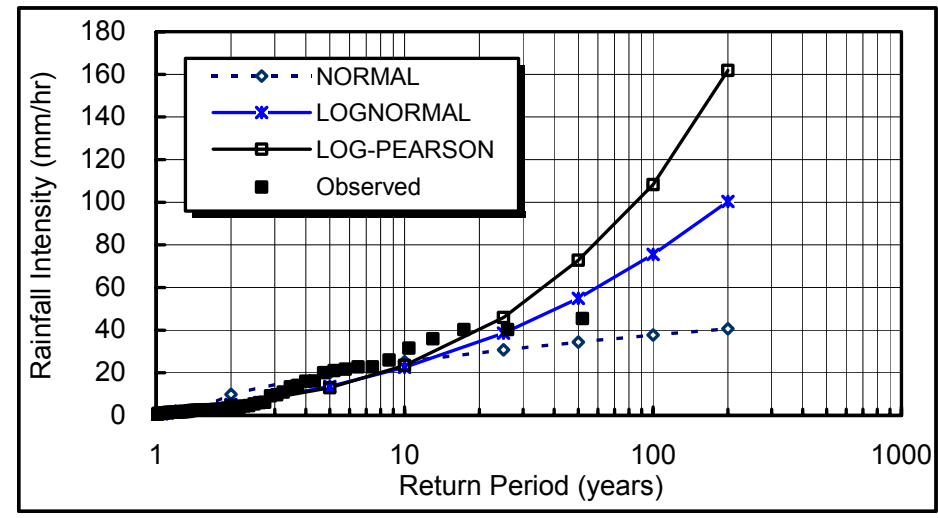

Figure 18.5 Rainfall intensity.

\subsection{Antecedent Soil Moisture}

The antecedent soil moisture (ASM) content is normally considered as an important parameter for runoff generation. This parameter indicates degree of saturation of the soil and may have a direct impact on the shape of runoff hydrograph, and the effectiveness of green roof for runoff volume reduction and peak flow attenuation. Data of the antecedent soil moisture content at the site was collected by two ESI GroPoint ${ }^{\mathrm{TM}}$ soil moisture sensors which were installed within the garden substrate, with sensor \#1 near the top, and sensor \#2 near the bottom. Figure 18.6 shows measurements of ASM with the upper and lower sensors.

During the observation period in 2003, 2004 and 2005, the highest percentage of ASM measured with the lower sensor was $44.2 \%$ on the date of June 13, 2005 during the time period from 17:04 to 20:18, and the corresponding upper sensor measurement was not available since the unit was not functioning at the time. By comparison, the highest percentage of ASM measured with the upper sensor was $31.3 \%$ on the date of May 7, 2003, and the corresponding lower sensor measurement was 40.3\%. Figure 18.6 shows a comparison of the percentage of ASM measured with the upper and lower censors. Figure 18.7 illustrates the correlation between the upper and lower sensor measurements. In the figure, the data is fitted by a logarithmic function with the $\mathrm{R}$ squared value of 0.43 , which was better than the correlation fitted by a linear equation. 


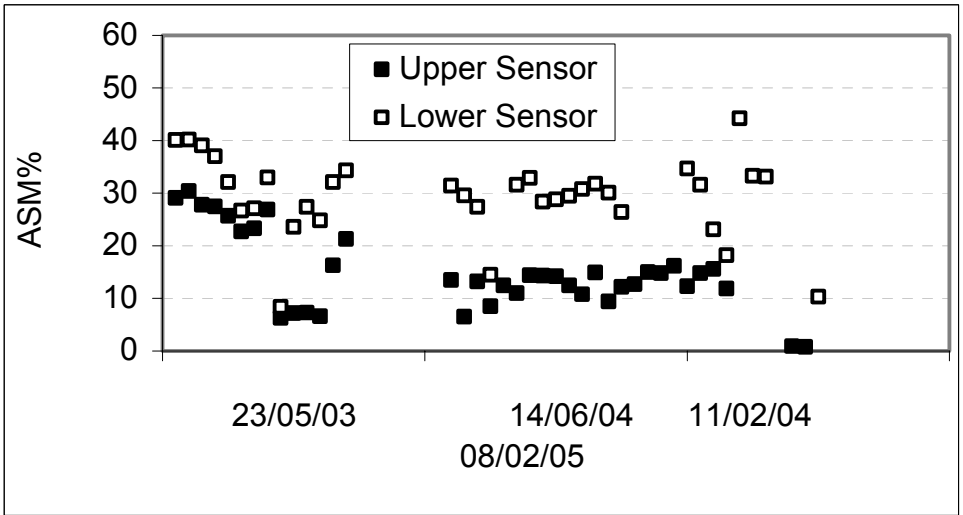

Figure 18.6 Percentage of antecedent soil moisture (ASM).

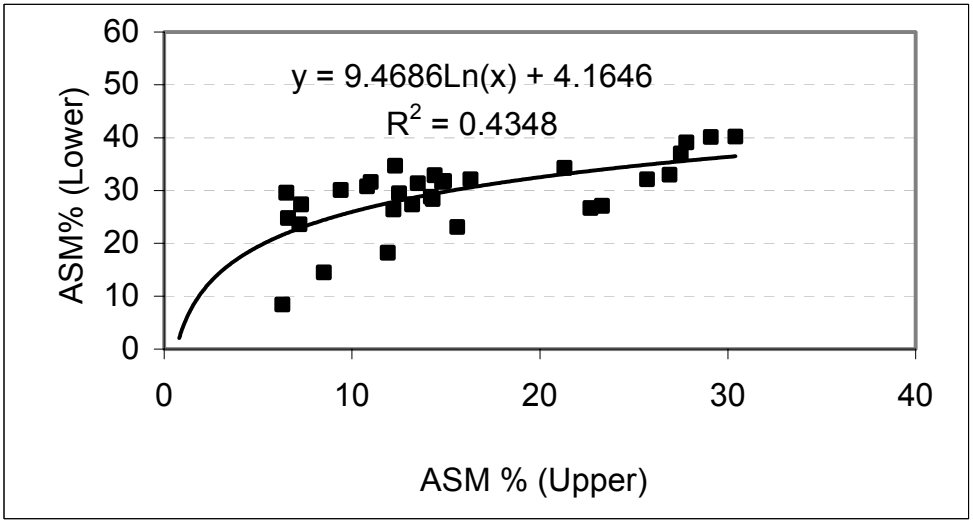

Figure 18.7 Antecedent soil moisture upper sensor vs. lower sensor.

Sample measurements of the percentage of ASM are fitted by probability distributions as shown in Figures 18.8 and 18.9, respectively. Based on the three commonly used distributions, it is found that the normal distribution is capable of fitting both the upper and lower sensor measured data well. The log Pearson distribution can fit the upper sensor measured data well, but is likely to underestimate the lower censor measured percentage of ASM. In contrast, the log Pearson distribution appears consistently to overestimate both the upper sensor and lower sensor measured data, as indicated in the two figures. 


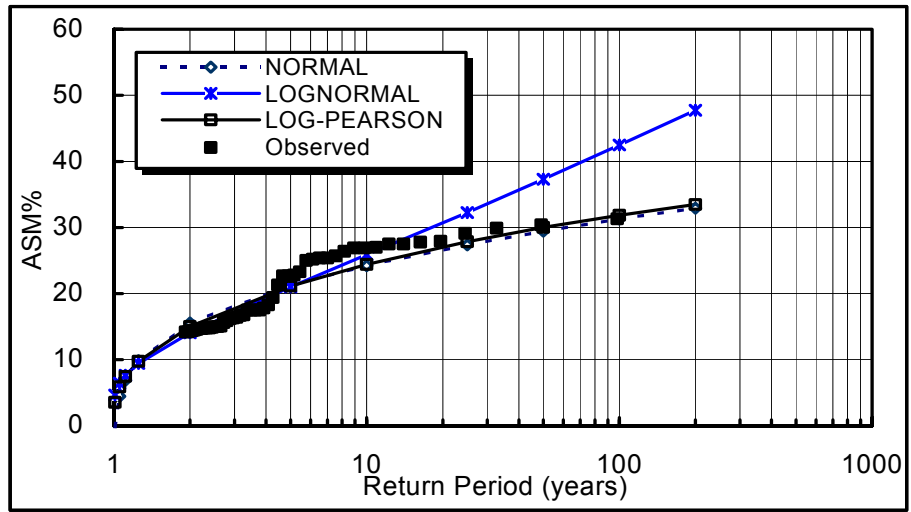

Figure 18.8 Antecedent soil moisture upper sensor.

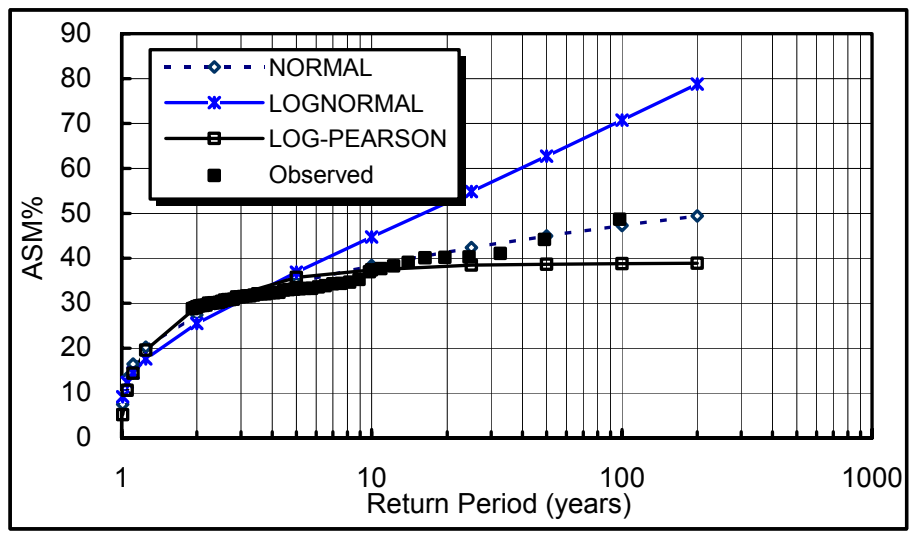

Figure 18.9 Antecedent soil moisture lower sensor.

\subsection{Runoff Characteristics}

For the control roof (the area without vegetation), the maximum runoff event volume was $42.87 \mathrm{~L} / \mathrm{m}^{2}$ observed on the date of September 27, 2003, and the corresponding runoff volume with a value of $27.54 \mathrm{~L} / \mathrm{m}^{2}$ observed on the same date was also the maximum volume among all the sample runoff events monitored from the garden roof. In terms of the two observed values, 
the runoff volume reduction is estimated as $35.8 \%$. For this rainfall event, the total rainfall depth is $41.6 \mathrm{~mm}$ with a mean intensity of $3.8 \mathrm{~mm} / \mathrm{hr}$, and the percentage of ASM from the upper and lower sensor are not available due to the malfunctioning of the units. A comparison of the runoff volumes from the garden and control roof is shown in Figure 18.10. The correlation between the runoff volumes measured from the garden and control roof is shown in Figure 18.11 with the R squared value of 0.5 .

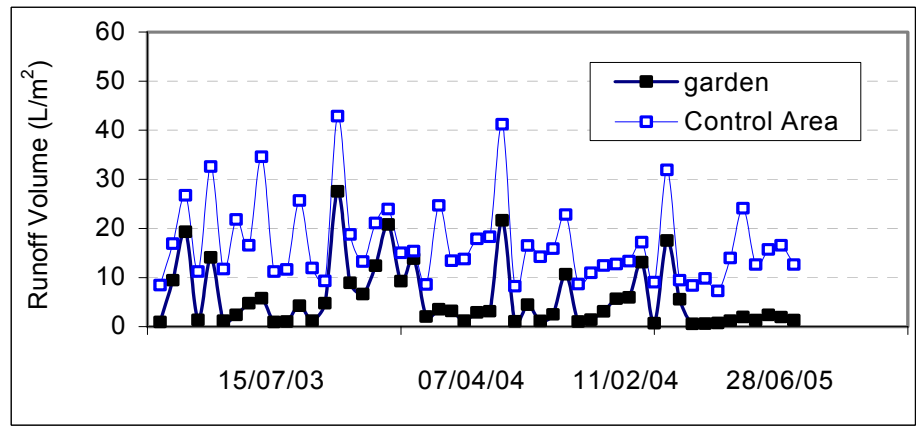

Figure 18.10 Runoff volume garden vs. controlled roof.

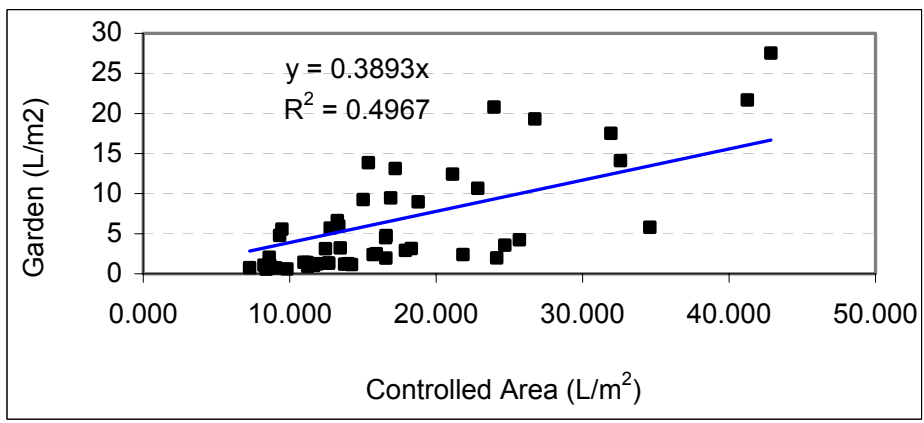

Figure 18.11 Runoff volume garden vs. controlled roof.

For the control roof, the maximum peak flow rate with a value of 100.86 $\mathrm{L} / \mathrm{hr} . \mathrm{m}^{2}$ was observed on the date of August 2, 2003, the corresponding flow rate from the garden is $10.68 \mathrm{~L} / \mathrm{hr}^{2} \mathrm{~m}^{2}$, indicating a $90 \%$ peak attenuation. A comparison of peak flows observed from the garden and controlled roof is shown in Figure 18.12. As indicated in the figure, the garden is very effective for peak flow attenuation. With the R squared value of 0.29 , the 
peak flow rates from the garden and control roof are not closely correlated. The weak relationship is mainly caused by the three scattered points representing the three highest flow rates observed from the garden as shown in Figure 18.13. There will be a significant improvement in the correlation if the three points were excluded.

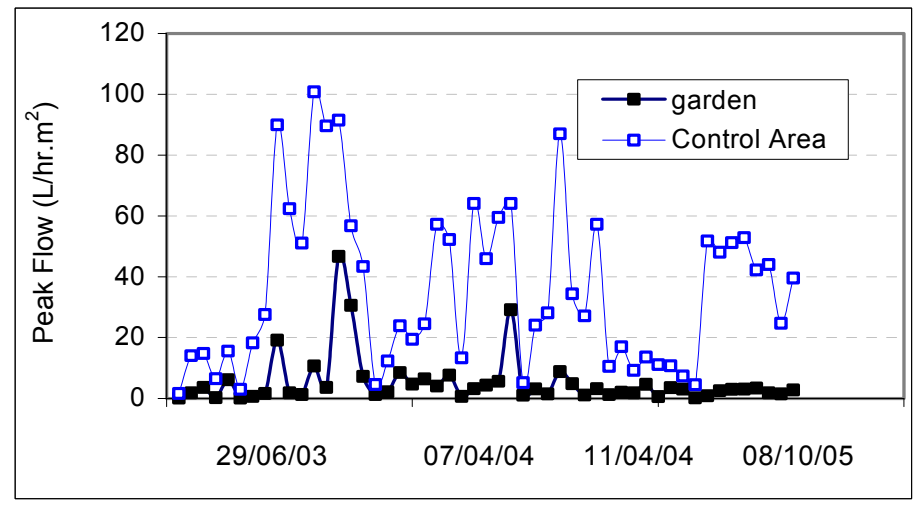

Figure 18.12 A comparison of peak flows from the garden and controlled roof.

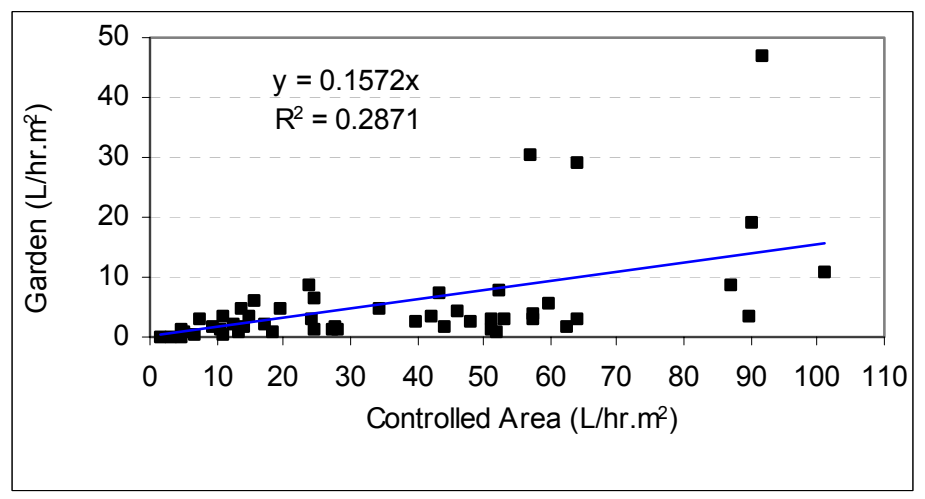

Figure 18.13 Flow rate garden vs. controlled roof.

Figure 18.14 shows plots of runoff volumes versus peak flow rates for the control roof at the site. It appears that there is no strong correlation between the two observations, and the relationship is also indefinitive based on the monitoring data from the garden as shown in Figure 18.15. 


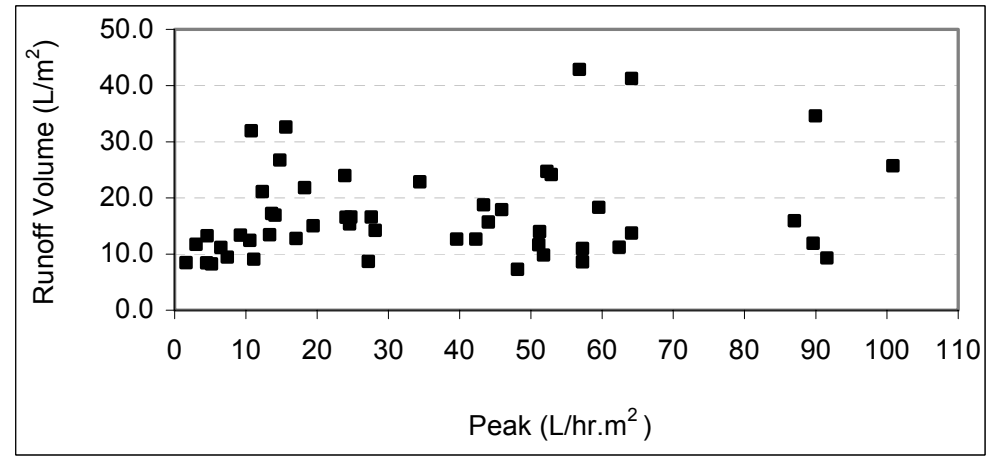

Figure 18.14 Controlled roof runoff volume vs. peak flow rate.

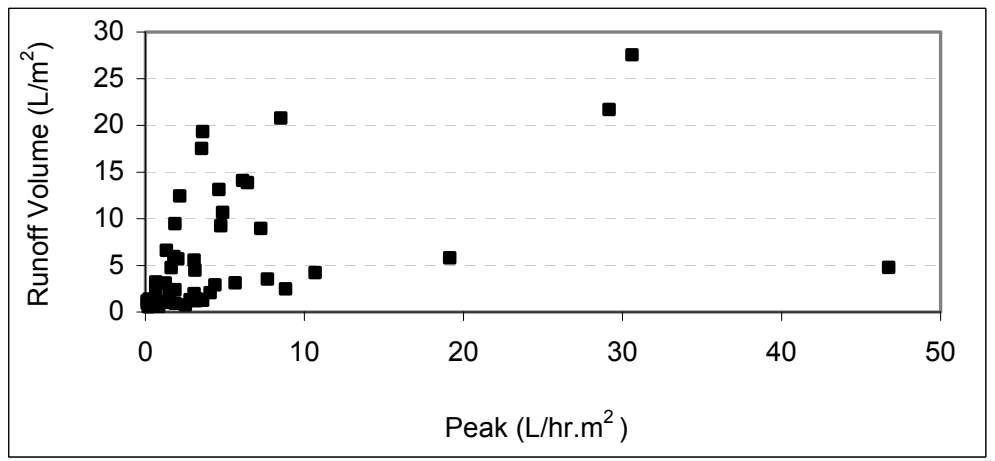

Figure 18.15 Garden runoff volume vs. peak flow rate.

The characteristics of peak flow rates are also analyzed by fitting probability distributions to the observed data. Figures 18.16 and 18.17 shows fitted probability distributions for peak flows from the garden and control roof, respectively. In Figure 18.16, the log normal distribution fits the observed data better than either the normal or log Pearson distribution. The normal distribution tends to overestimate peak flow rates for flows with a relatively low magnitude, and underestimate peak flow rates for flows with a relatively high magnitude. However, in Figure 18.17, the log normal distribution tends to overestimate peak flow rates for flows with a higher magnitude. For the control roof peak flows, both the normal and log Pearson distribution appear to fit the observed data better than the log normal distribution. 


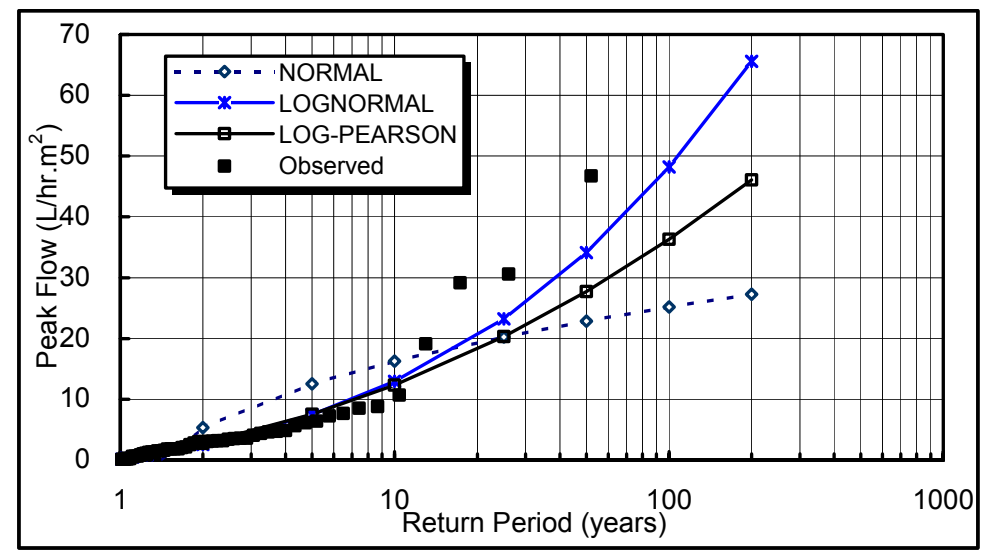

Figure 18.16 Garden peak flow.

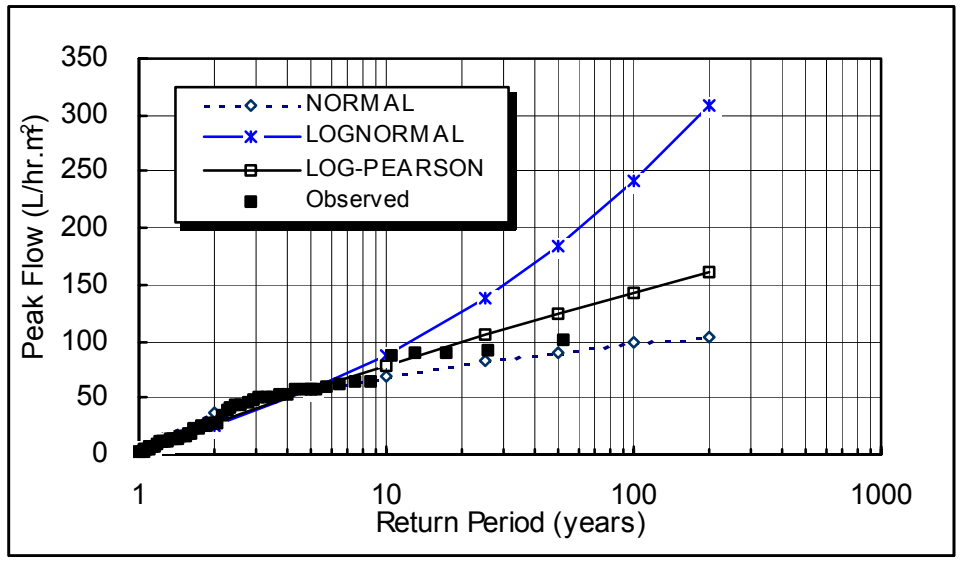

Figure 18.17 Controlled roof peak flow.

Figures 18.18 and 18.19 illustrate the fitted probability distributions for the runoff volumes observed from the garden and control roof, respectively. In Figure 18.18, the log normal distribution fits the observed data better than either the normal or log Pearson distribution. The normal distribution tends to underestimate runoff volume for runoff events with a relatively higher magnitude, whereas log Pearson may overestimate runoff volumes for runoff events with a relatively higher magnitude. In contrast, Figure 18.19 shows that the $\log$ Pearson distribution can fit the observed data better than the log 
normal and normal distributions. Both distributions tend to underestimate runoff volumes for runoff events with a relatively higher magnitude. From the two figures, it is safe to say that the normal distribution is not the desirable choice for fitting runoff volume data observed from both the garden and control roof.

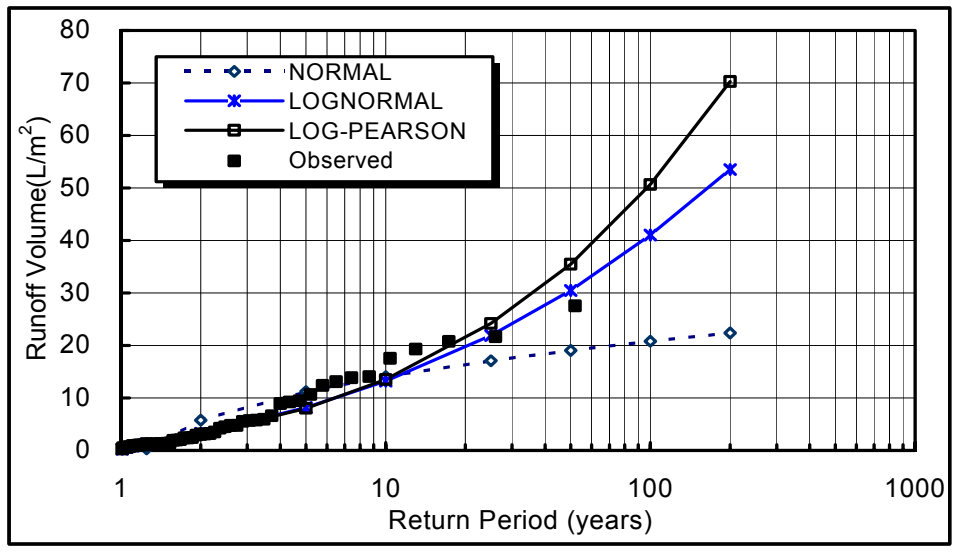

Figure 18.18 Garden runoff volume.

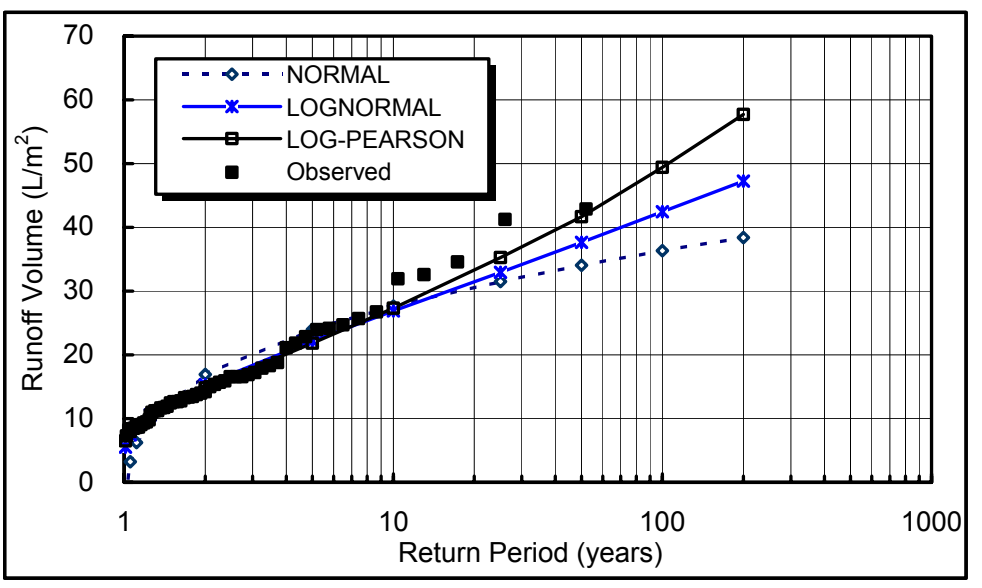

Figure 18.19 Controlled roof runoff volume. 


\subsection{Rainfall-Runoff Process}

\subsubsection{Runoff Volume}

One of the important aspects in the characterization of urban stormwater is to establish rainfall-runoff transformation, with which stormwater runoff can be estimated from rainfall. For this purpose, major parameters associated with runoff generation mechanism are analyzed in an attempt to establish quantitative relationships. Figure 18.20 shows the correlation between the rainfall depth and runoff volume monitored from the control roof. The figure reveals a good relationship between the rainfall-runoff transformation processes with the $\mathrm{R}$ squared value of 0.94 . However, the measured runoff volumes of some events were slightly larger than the corresponding measured rainfall volumes, indicating some equipment problems.

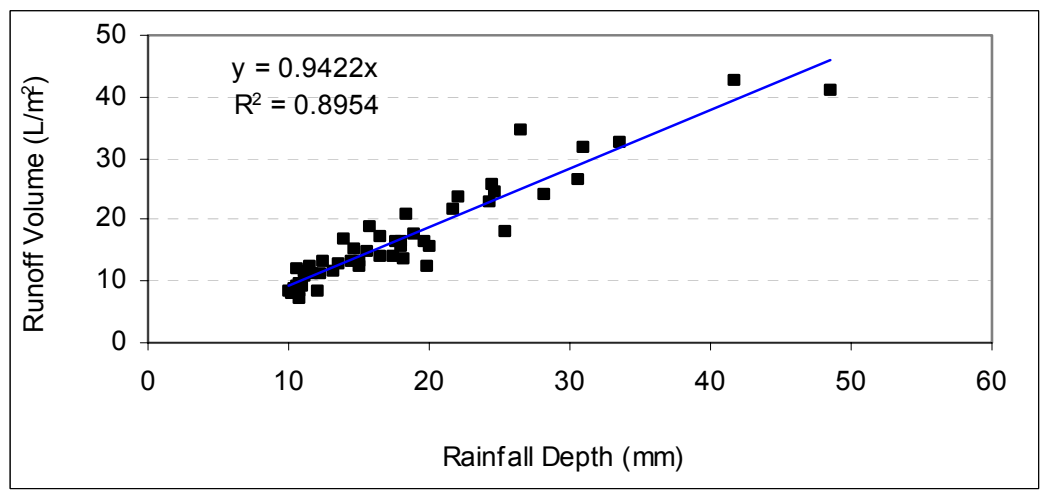

Figure 18.20 Control roof runoff volume vs. rainfall depth.

Figure 18.21 shows the relationship between the rainfall depth and runoff volume with sample data from the garden. With the $\mathrm{R}$ squared value of 0.43 , the correlation between the rainfall and runoff for the garden is much weaker compared to the relationship for the control roof. The finding appears to be reasonable considering the potential factors involved in the rainfall-runoff process under green roof conditions. The estimation of runoff volume from green roof may be more complicated by considering other major factors such as the antecedent soil moisture condition or soil moisture content. In addition, roof garden runoff generation mechanism is also linked with infiltration and evaporation processes. 


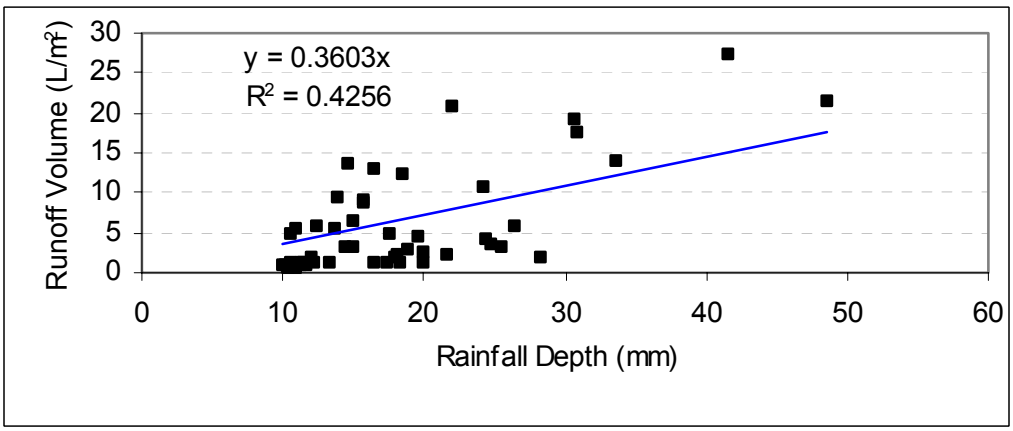

Figure 18.21 Garden runoff volume vs. rainfall depth.

It is recognized that runoff generation not only depends on rainfall volume but also rainfall intensity. However, the monitored data from the rooftop appears to indicate that there is no strong correlation between runoff volume and rainfall intensity. It may be attributed to the weak correlation between rainfall volume and rainfall intensity as illustrated in Figure 18.3. As shown in Figure 18.22, rainfall events with a high intensity may not generate a high volume of runoff, and events with a low intensity are still able to produce a high runoff volume. The patterns between the rainfall volume and rainfall intensity appear to be similar for both the garden and control roof.

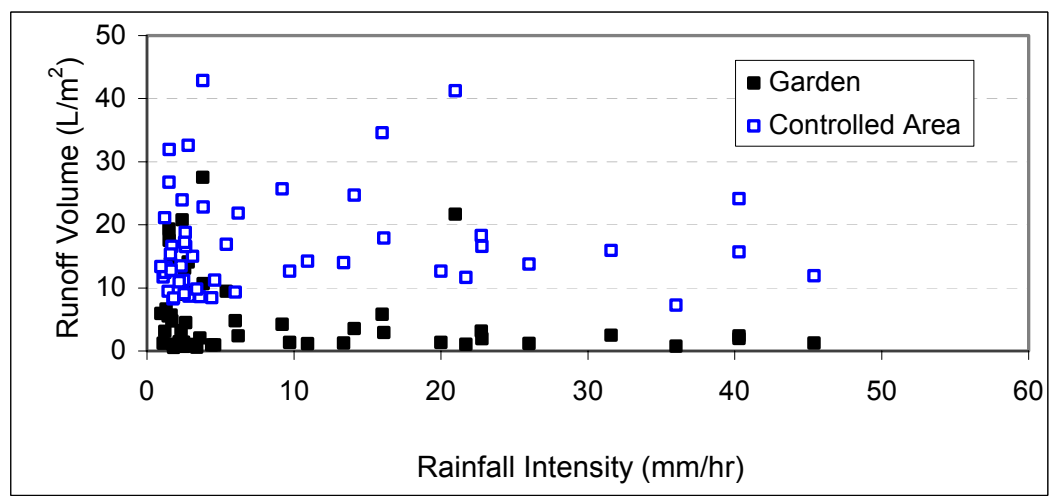

Figure 18.22 Runoff volume vs. rainfall intensity. 


\subsubsection{Peak Flow Rate}

Another important characteristic of stormwater runoff is peak flow rate. It is of significance to examine the relationship between the rainfall and peak flow rate as part of the effort to characterize the rainfall-runoff transformation process on the rooftop. Figure 18.23 shows the plot of rainfall volume against peak flow rate monitored from the control roof. The figure indicates that the peak flow rate from the control roof is not particularly related to the rainfall volume. The rainfall event with the highest rainfall volume does not produce the highest peak flow rate; a higher peak flow rate is produced by the rainfall events with a relatively low magnitude of rainfall volume.

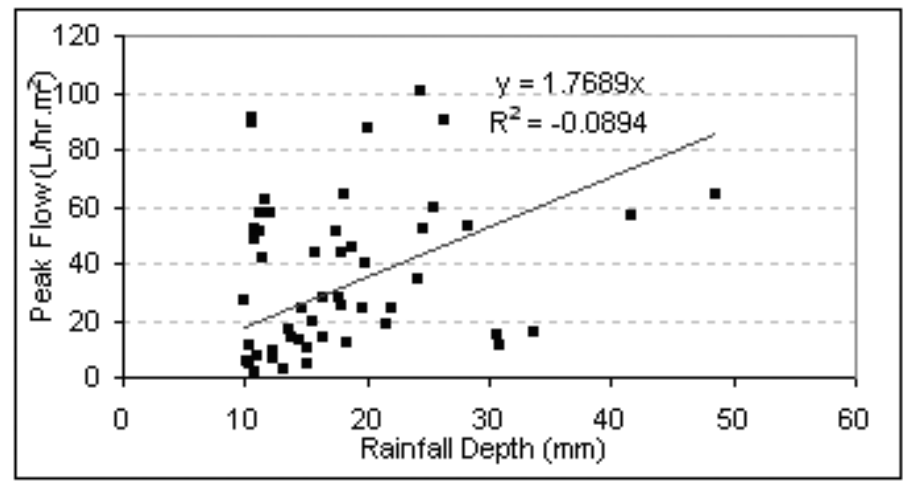

Figure 18.23 Control roof peak flow rate vs. rainfall depth.

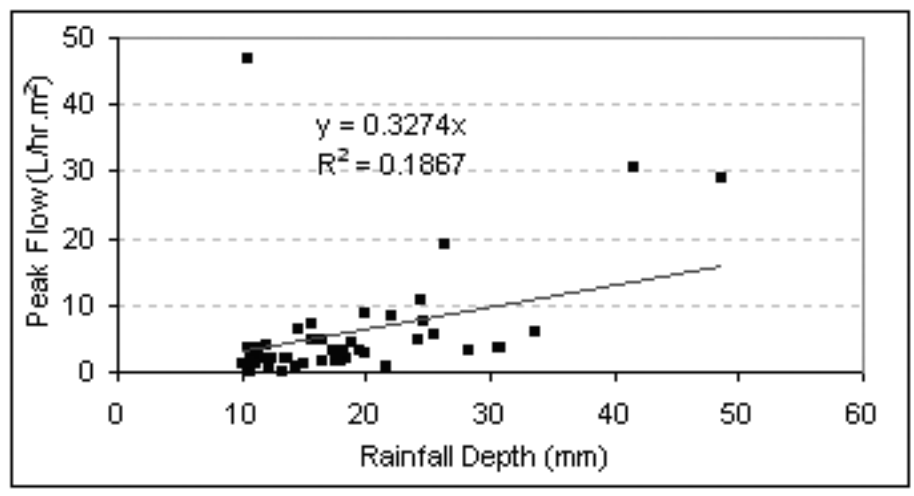

Figure 18.24 Garden peak flow rate vs. rainfall depth. 
By comparison, the correlation between the rainfall volume and peak flow rate is also weak based on the roof garden data. But this correlation as shown in Figure 18.24 is somewhat more defined than the correlation for the control roof. From the figure, it is also noted that there is an apparent trend among the plotted points except for one rainfall event with a rainfall depth of $10.6 \mathrm{~mm}$ on August 11, 2003 that produces the highest peak flow rate of $46.74 \mathrm{~L} / \mathrm{hr}^{2} \mathrm{~m}^{2}$. This exceptional point may be an outlier caused by measurement error. The data from the garden and control roof also reveals a weak correlation between the peak flow rate and rainfall intensity as shown in Figures 18.25 and 18.26. Since the garden infiltration rate is not monitored, it is difficult to determine conditions for overland flow based on the rainfall intensity data alone.

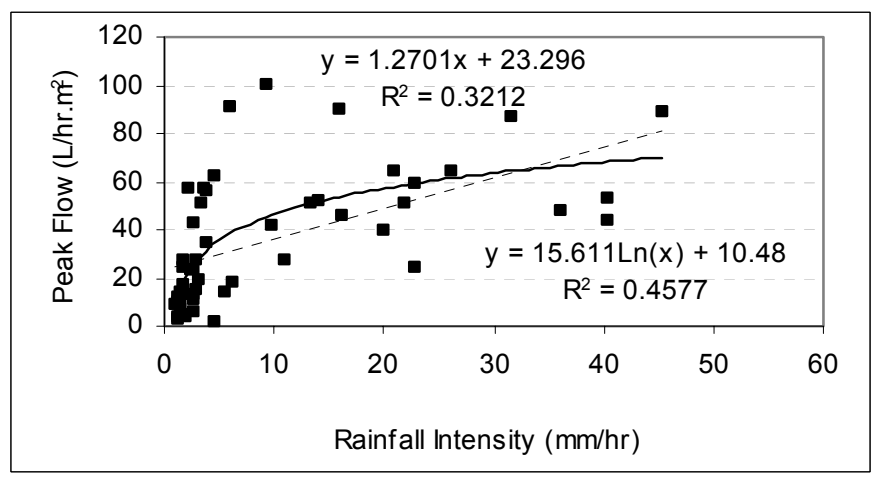

Figure 18.25 Controlled roof peak flow rate vs. rainfall intensity.

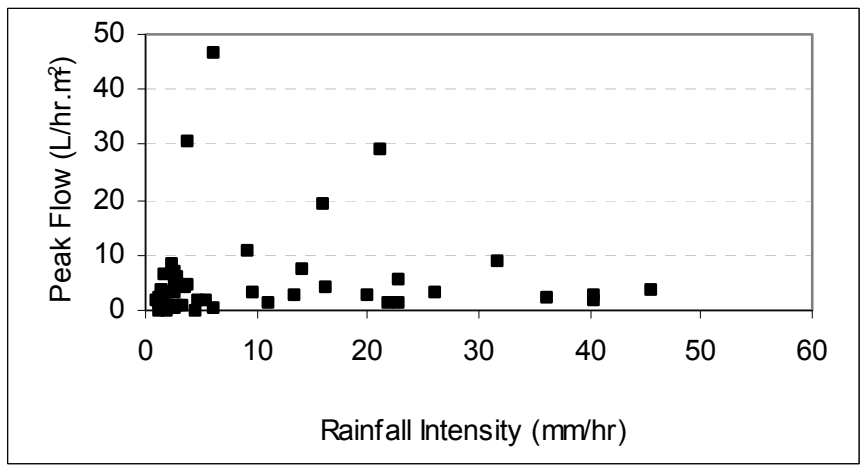

Figure 18.26 Garden peak flow rate vs. rainfall intensity. 


\subsubsection{Antecedent Soil Moisture}

It is well known that runoff not only depends on rainfall characteristics such as rainfall volume and intensity, but also the characteristics of the soil such as antecedent soil moisture content. For two rainfall events with the same characteristics (e.g. same rainfall volume and intensity), the generated runoff may not be the same in terms of runoff volume or peak flow rate if the antecedent soil moisture content before the two rainfall events are significantly different. However, when the ASM approaches the fully saturated condition (e.g. 30-40\%), the runoff characteristics (e.g. volume and intensity) may not be dependent on the ASM. To evaluate this important parameter, the monitored ASM with the upper sensor is plotted against the runoff volume as shown in Figure 18.27. From the figure, it appears that there is no clearly defined correlation between the percentage of ASM and runoff volume. The lower sensor monitored data (Figure 18.28) also indicates that the runoff volume is not apparently dependent on the percentage of ASM. Similar conclusions are also reached by correlating the peak flow rate with the percentage of ASM as shown in Figures 18.29 and 18.30.

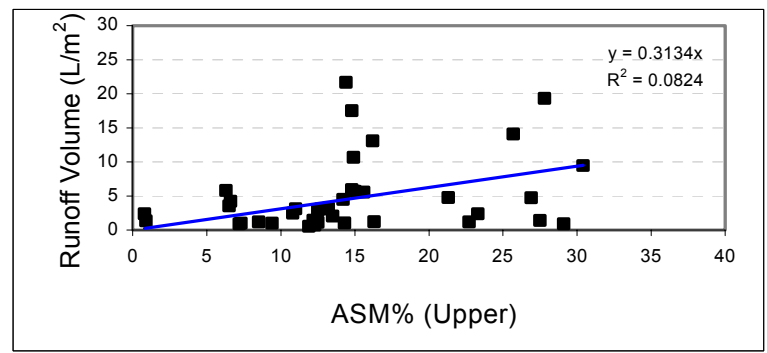

Figure 18.27 Garden antecedent soil moisture (upper) vs. runoff volume.

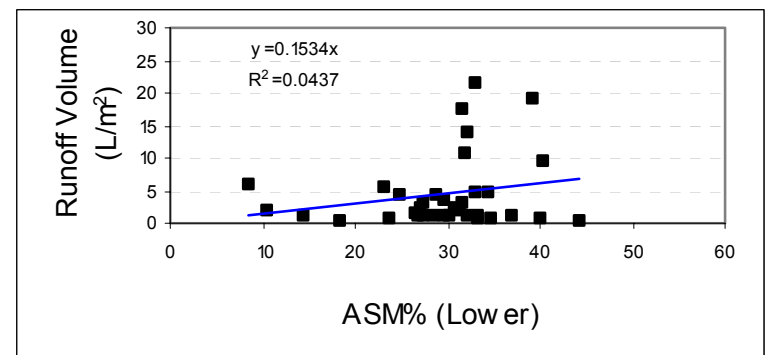

Figure 18.28 Garden antecedent soil moisture (lower) vs. runoff volume. 
Theoretically, for the same rainfall event, runoff volume increases when the percentage of ASM increases until saturation. It is also true for peak flow rates. The antecedent soil moisture condition also affects infiltration rate. However, in this study, no equipment was installed for monitoring soil infiltration process. As a result, no infiltration data can be used for correlation analysis.

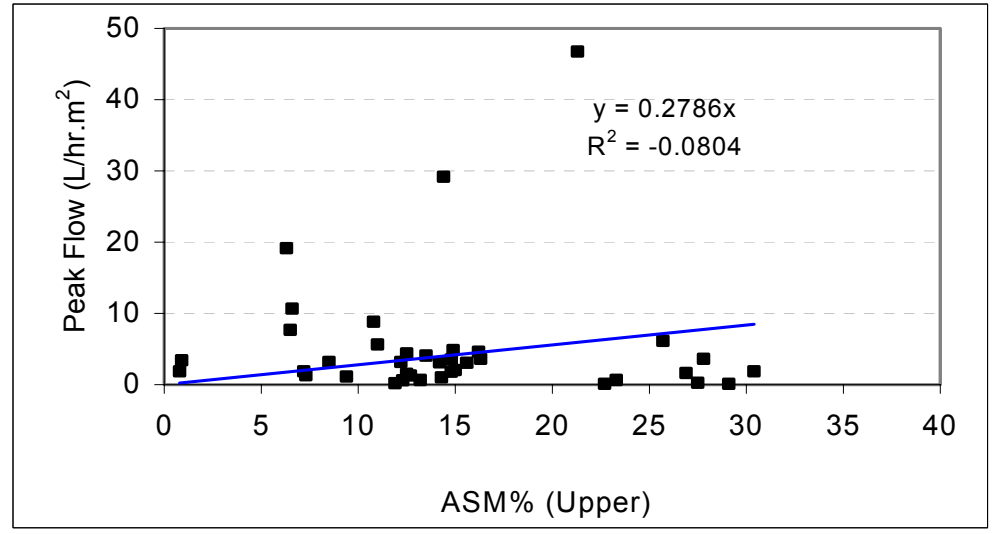

Figure 18.29 Garden antecedent soil moisture (upper) vs. peak flow rate.

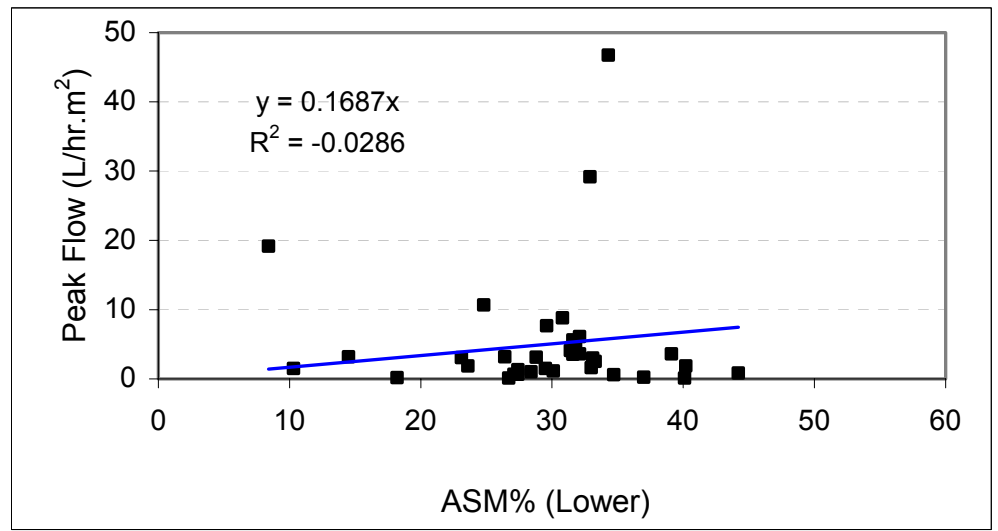

Figure 18.30 Garden antecedent soil moisture (lower) vs. peak flow rate. 


\subsubsection{Runoff Coefficient}

Instead of trying to identify all the potential factors associated with the rainfallrunoff transformation process, and then trying to determine which factor plays a more significant role in the process, it is of interest to evaluate the collective impact of these factors on the rainfall-runoff process in terms of certain lumped parameters. One of such commonly used parameters is the runoff coefficient. In cases where no data is available for soil characteristics such as soil moisture content and infiltration rate, it is difficult to incorporate infiltration or other physical processes into the rainfall-runoff transformation. Under such conditions, using a lumped parameter in rainfall-runoff formulation can be advantageous.

Runoff coefficient is an important quantitative index for runoff estimation, a direct measure of rainfall-runoff transformation. Runoff coefficient may be estimated as the ratio of direct runoff over rainfall volume. Data analysis shows that the values of runoff coefficient are normally greater than 0.6 for the control roof, and between zero and one for the garden. Figures 18.31 and 18.32 shows the correlation between the runoff volume and runoff coefficient for the control roof and the garden, respectively. For the control roof as shown in Figure 18.31, it is noted that runoff coefficients of some events are larger than one, indicating problems with some measurements. The runoff volume is not strongly correlated with the runoff coefficient as expected. The relatively weak relationship is more or less affected by the two scattered points on the top of the figure and may be attributed to poor measurements.

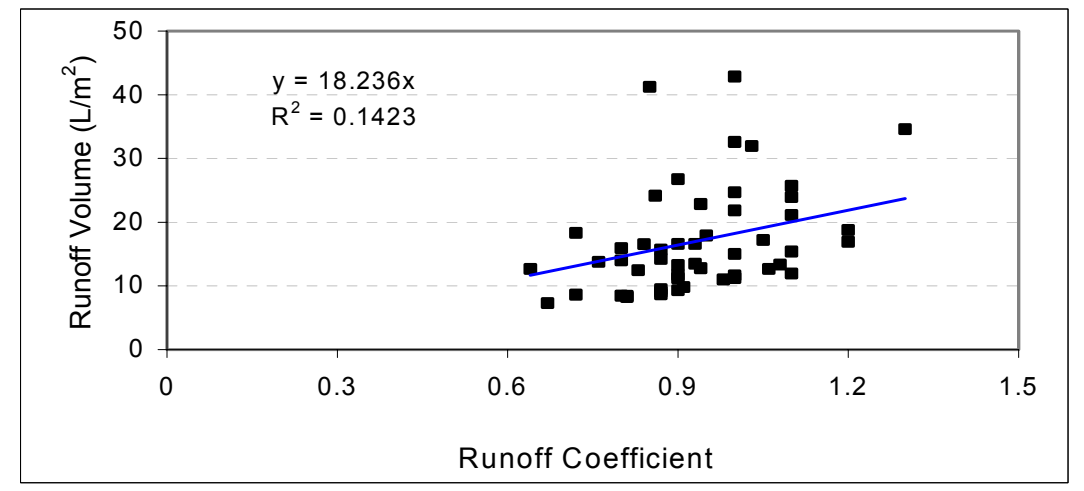

Figure 18.31 Control roof runoff volume vs. runoff coefficient. 


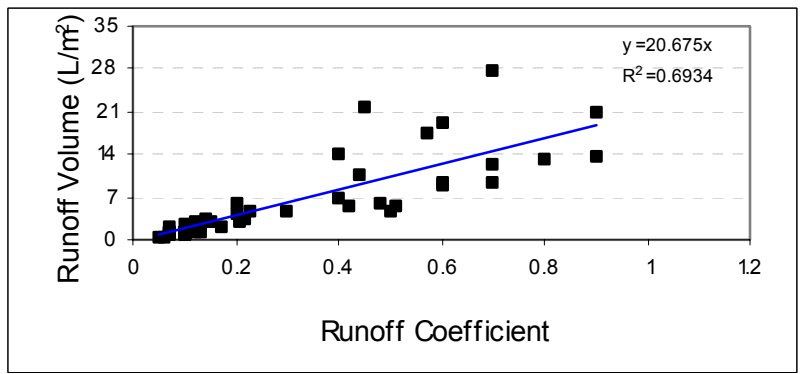

Figure 18.32 Garden runoff volume vs. runoff coefficient.

In contrast, the runoff volume and runoff coefficient correlation for the garden is more clearly defined with the R squared value of 0.69 as shown in Figure 18.32.

Besides runoff volumes, it may be also interesting to examine the impact of runoff coefficient on peak flow rates. To characterize the relationship between the peak flows and runoff coefficient, measured peak flows are plotted against runoff coefficient in Figures 18.33 and 18.34 for the control roof and garden, respectively. The two figures clearly show that the correlation between the peak flow and runoff coefficient is not definitive.

Similar conclusions are reached by analyzing peak flow rate against the antecedent soil moisture content data as shown in Figures 18.35 and 18.36. Theoretically, if all other conditions remain the same including the rainfall characteristics, runoff coefficient should increase as the percentage of antecedent soil moisture increases until saturation. In other words, for the same rainfall volume, increasing the percentage of antecedent soil moisture means decreasing rainfall loss to soil, increasing the total volume of runoff, which results in an increase in runoff coefficient.

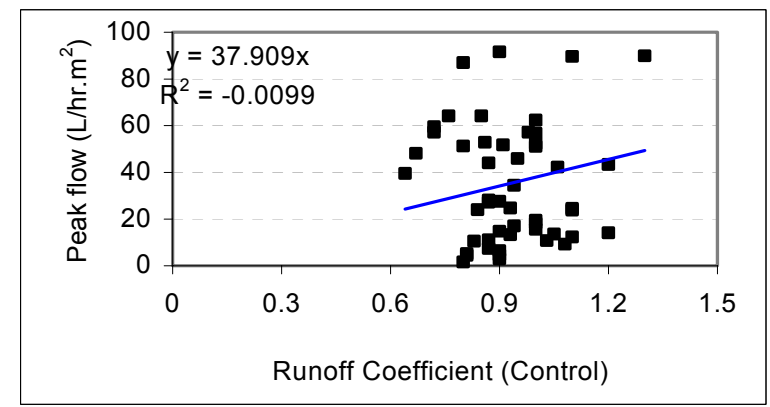

Figure 18.33 Control area peak flow rates vs. runoff coefficient. 


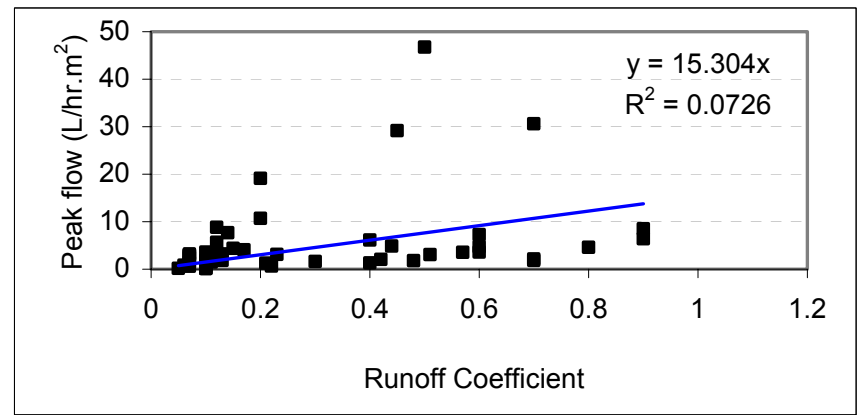

Figure 18.34 Garden peak flow rates vs. runoff coefficient.

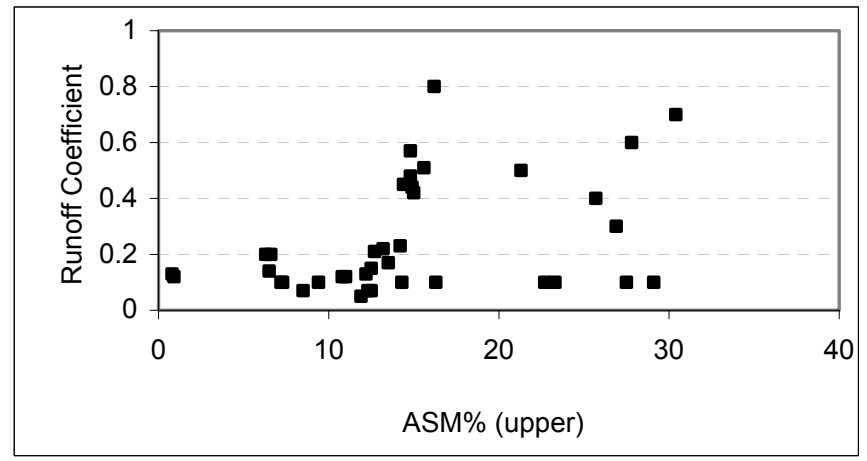

Figure 18.35 Garden antecedent soil moisture (upper) vs. runoff coefficient.

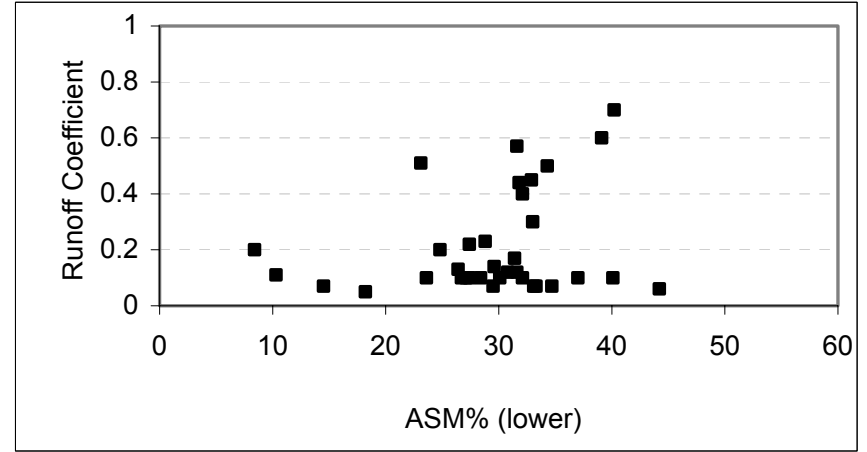

Figure 18.36 Garden antecedent soil moisture (lower) vs. runoff coefficient. 


\subsection{Conclusions}

Statistical analysis of the measured rainfall data indicates that the correlation between rainfall volume and intensity appears to be very weak. Some commonly used probability distributions can be used to fit sampled rainfall data, but the Log Pearson and Normal distributions are more likely to overestimate or underestimate rainfall statistics, and the Log normal distribution provides an estimate that is in between. By contrast, the normal distribution can fit the antecedent soil moisture data (obtained from both the upper and lower sensors) well. Analysis of monitored runoff data reveals that roof garden is effective for stormwater volume reduction and peak flow attenuation. Even with only $140 \mathrm{~mm}$ of soil, the roof garden reduced the runoff significantly for some rainfall events. The correlation between runoff volume from the garden and control roof is stronger than the correlation between peak flows from the two roof surfaces. For peak flow data either monitored from the garden or control roof, the Log normal distribution provides the most conservative estimates of peak flow rates compared with that from the normal and Log Pearson distributions. In contrast, the Log normal distribution may provide the most conservative estimates of runoff volume which are actually in between the normal and Log Pearson estimates. Based on the data monitored either from the garden or control roof, there is no apparent correlation between runoff volume and peak flow rates.

For the rainfall-runoff transformation, correlation analysis indicates that there is a strong correlation between the rainfall and runoff volume in terms of the data collected from control roof. By comparison, the relationship between the rainfall and runoff volume is not strong, based on the data from the garden. The correlation between the peak flow rates and rainfall volume or intensity is also weak based on the data from both the garden or control roof. There is no apparent correlation between the antecedent soil moisture content and runoff volumes or peak flows. The correlation between runoff volume and runoff coefficient from garden monitored data is stronger than the correlation for the control roof. This may be attributed to the measured runoff at the control roof in which the runoff exceeded rainfall. The data collected from the garden and control roof indicate that peak flows appear to be independent of runoff coefficient. Based on roof garden data, it appears no apparent correlation was found between the antecedent soil moisture content and runoff coefficient.

Some of the findings in this study are counter-intuitive and may be attributed to poor measurements. Field monitoring of roof runoff is 
challenging compared to the conventional monitoring of stormwater best management practices. Accurate measurement of flow at roof drains is difficult as the flow may be partial or full pipe conditions. Moreover, flow sensors such as weirs or electromagnetic flow meters work only over a certain range of flows. As a result, the current established methods for stormwater design may not be easily adapted for green roofs.

\section{References}

Bass, B. and B. Baskaran. 2003. Evaluating Rooftop and Vertical Gardens as an Adaptation Strategy for Urban Areas. Institute for Research and Construction, NRCC-46737, Project no. A020, CCAF Report B1046. Ottawa, Canada: National Research Council.

Jennings, G., Hunt, B., Moran, A (2003) A North Carolina Field Study to Evaluate Green roof Runoff Quantity, Runoff Quality, and Plant Growth, ASAE Annual International Meeting, Las Vegas, Nevada, USA, 27-30 July 2003.

Kohler, M., Schmidt, M., Grimme, F.H., Laar, M., Paiva, V.L.A., and Tavares, S. 2002. Green roofs in Temperate climates and in the hot-humid tropics - far beyond the aesthetics. Environmental Management and Health. 13(4) 382-391

Li, J. (2006) Evaluation of stormwater performance of green roofs in the City of Toronto. Report prepared for the Government of Canada's Great Lakes Sustainability Fund.

Liesecke, H. (1993) Wasserruckhaltung bei extensiven dachbegrunungen, Deutscher Gartenbau, 47 (34): 2142-2147.

Liesecke, H. (1998) Das Retentionsvermogen von Dachbegrunungen, Stadt Und Grun, 47:46-53.

Liptan, T. (2003). Planning, Zoning and Financial Incentives for Ecoroofs in Portland, Oregon. Proceedings from Greening Rooftops for Sustainable Communities, First North American Green Roof Infrastructure Conference, May 29-30th, Chicago.

Liu, K. (2003). Engineering Performance of Rooftop Gardens Through field evaluation, Proceedings of the 18th International Convention of the Roof Consultants Institute: 13-16 March, 2003, Tampa, FL, pp. 93-103.

Rowe, D., Rugh, C., Vanwoert, N., Monterusso, M., Russell, D. (2003) Green Roof Slope, Substrate Depth, and Vegetation Influence Runoff, Michigan State University Dept. of Horticulture and Michigan State University Dept. of Crop and Soil Sciences, Greening Rooftops for Sustainable Communities Conferenece, May 29-30, 2003., Chicago.

Thompson, A., (1998), Grass-roofs movement in landscape architecture, The magazine of the American Society of Landscape Architects, 88:47-51.

Toronto and Regions Conservation Authority (TRCA) (2005). York University Rooftop Garden Monitoring Report: 2003 - 2004 Monitoring Seasons, Reported prepared for Great Lakes Sustainability Fund, Ministry of Environment, and City of Toronto. 
